\title{
Particle number and particulate mass emissions of heavy duty vehicles in real operating conditions
}

\author{
Lukasz Rymaniak ${ }^{1, *}$, Andrzej Ziolkowski ${ }^{1}$, and Dawid Gallas ${ }^{1}$ \\ ${ }^{1}$ Poznan University of Technology, Faculty of Machines and Transport, ul. Piotrowo 3, 60-965 Poznan, Poland
}

\begin{abstract}
The article investigates the issue of PM emissions from HDV vehicles. The theoretical part discusses the problem of emission of this toxic compound in terms of particle structure taking into account the mass and dimensions of PM. Next, the methodology of the research and the results of the measurements performed under the conditions of actual operation were presented. The test drive routes were chosen in accordance with the operational purpose of the selected test vehicles. Two heavy vehicles were used for the study: a tractor with trailer and an eighteen meter long city bus. The test vehicles complied with the Euro V standard, with the second vehicle additionally complying with the EEV standard and being equipped with a DPF. The analysis of the research results was performed in the aspect of determining the operating time densities of vehicles and their drive systems as well as defining their emission characteristics and ecological indicators. PM and PN emissions were measured in the tests and particle size distribution was determined. It was shown that the exhaust gas aftertreatment system used in the city bus had a positive influence on the ecological indicators and had contributed to the reduction of PN emissions for heavier particles.
\end{abstract}

\section{Introduction}

The automotive industry represents a significant share of the global $\mathrm{CO}_{2}$ emissions. All internal combustion engines manufactured for vehicles must meet specific emissions requirements. Depending on the region, there are different standards for the type approval and limit values of emissions of particular harmful substances [1]. With the introduction of the Euro $5 \mathrm{~b}$ norm for passenger cars (PC) and Euro VI for heavy-duty vehicles (HDV), the control of particulate matter (PM) emissions has been extended to include their numbers - indication: particle number (PN) [2]. PM emissions are a very serious problem due to their composition and toxicity. For example, in terms of size, it was found that particles with a diameter greater than $10 \mu \mathrm{m}$ accumulate in the upper respiratory tract, whereas particles with a diameter of 2.5 $\mu \mathrm{m}$ enter the deeper parts of the lungs, where they are difficult to excrete and begin to accumulate [3-5]. It is therefore imperative to use construction and design solutions for vehicles that will have a beneficial effect on reducing the emissions of this compound both in terms of mass and number [6].

In the European Union the Euro standards apply to both PC and HDV. In the case of city buses, the standard expects engine dynamometer tests to be performed for the European Transient Cycle (ETC), European Load Response (ELR) and European Stationary Cycle (ESC) for Euro III-V norm and the World Harmonized Transient Cycle (WHTC) and World Harmonized Stationary Cycle (WHSC) for Euro VI. These tests relate to heavy duty vehicles, but the measurement procedures are performed for the internal combustion engines themselves in laboratories. It should be noted, however, that the results of laboratory tests may vary considerably from the actual emissions from a HDV, especially if the vehicle is equipped with a hybrid drive, for example. Hence, research in real operating conditions is being used increasingly more often. In this type of measurement it is possible to evaluate the emission of pollutants in a much larger range of engine operating parameters variability [7-10]. For HDVs, road tests are already necessary in terms of checking the emissions compliance of vehicles already in service [11]. On the other hand, for the PC type vehicles, real driving emissions (RDE) will appear in the type approval procedures starting on 1st of September 2017 [12, 13].

\section{Causes of PM emissions}

The process of PM formation is complicated and consists of many complex chemical and physical reactions, often occurring simultaneously. Decomposition of fuel into aromatic hydrocarbons or acetylene is assumed to be one of the main processes involved in PM formation. The basic building block of PM is the soot, which is formed from said fuel decomposition products. Among the main causes of soot formation in the engine combustion chamber are: locally too rich fuel mix $(\lambda<1)$, incorrect fuel injection parameters, low combustion temperature and cold engine start. The direct causes are: the temperature distribution, the concentration of substrates and combustion products, the pressure values, and the kinetics of the chemical reactions. Pure carbon can also

Corresponding author: lukasz.rymaniak@put.poznan.pl 
be formed in the cylinder of an internal combustion engine by endothermic $\mathrm{CO}$ decay.

The soot's outer structure, its dielectric properties, and the radical properties favor the absorption of various kinds of particles/impurities. In the field of internal combustion engine research $\mathrm{PM}_{\mathrm{TOTAL}}$ is defined as the organic or inorganic products collected on a filter through which the stream of diluted exhaust gas passes at $52 \pm 3{ }^{\circ} \mathrm{C}$ [14]. $\mathrm{PM}_{\text {TOtAL }}$ is divided based on the process of its formation into two basic fractions: $\mathrm{PM}_{\mathrm{SOF}}$ and $\mathrm{PM}_{\mathrm{INSOL}}$. The first is defined as a soluble fraction, while the second one is insoluble, the primary component of which is carbon resembling the structure of graphite, $\mathrm{PM}_{\mathrm{INSOL}}$ also contains water associated with sulphates, nitrates, metals and other carbon containing compounds. In addition, metals produced by the engine abrasive effects may appear in their composition. Metal particles from the exhaust aftertreatment system catalyst particles, can be particularly dangerous. The $\mathrm{PM}_{\mathrm{SOF}}$ soluble fraction consists of compounds derived from fuel $\mathrm{PM}_{\mathrm{FUEL}}$, formed by the combustion of an overly rich mixture, flame extinguishing process and lowering the combustion temperature due to expansion. This fraction also contains the $\mathrm{PM}_{\mathrm{LUBE}}$, that refer to components derived from the lubricating oil.

All of these causes of PM formation directly or indirectly affect the shape, structure, and properties of the created PM. The use of different technical solutions in modern compression ignition (CI) engines, the chemical composition of fuel and lubricants, power systems, supercharging and turbulence in the cylinder led to the formation of different particulate structures [15]. In terms of modern solutions used in the construction of internal combustion engines and vehicles one should consider their morphology in two aspects. The first one covers the most commonly considered physical parameters, i.e. the mass and the number (Fig. $1)$. On the other hand, the second aspect concerns the chemical parameters - the structure of the particle and its composition.
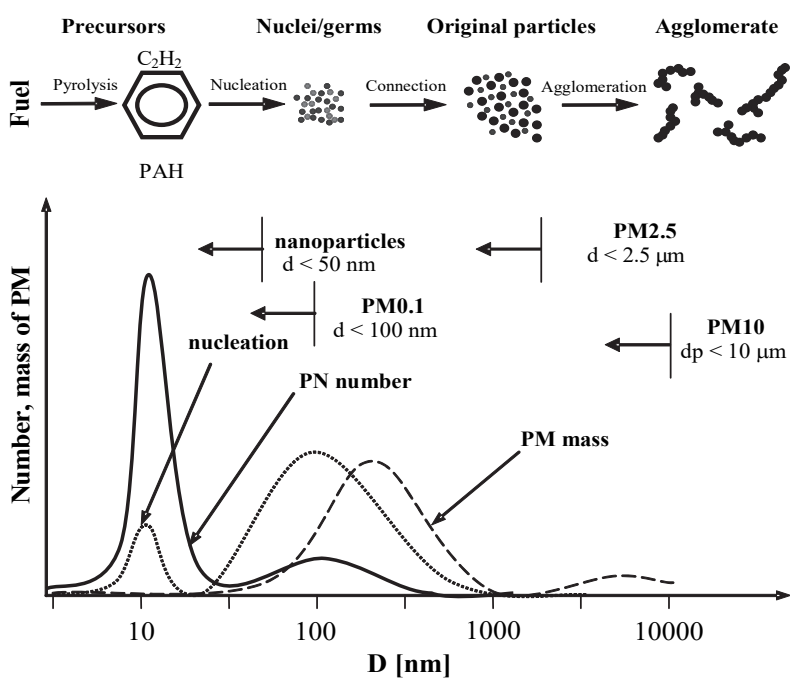

Fig. 1. The assumed pattern of particle formation along with size distribution $[16,17]$.

\section{Structure of PM}

Divergence in the number of particles can be analyzed mainly in terms of engine performance and vehicle performance. The mass of particulates is a parameter whose analysis is more difficult to perform. This is mainly due to the differences in particle structures that occur directly affecting their density and mass (Fig. 2). Measurement equipment usually assumes density of $1 \mathrm{~g} / \mathrm{cm}^{3}$ as a default value and a spherical shape of particulate matter. It is known, however, that these parameters can significantly differ in reality - apart from the size (diameter), solid particles are characterized by their volume and mass. For particles of spherical shapes, the physical significance of these parameters is known and is defined as the volume or mass of the material from which the particle is made, with and without considering internal voids.

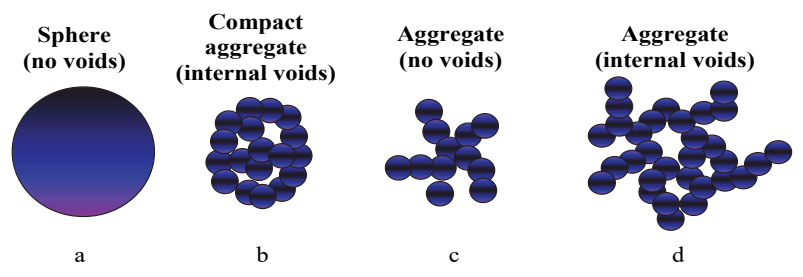

Fig. 2. Solid particle structures resulting from physicochemical formation characteristics and simplifications taken for measurement [18].

The volume of spherical particles and PM agglomerates without voids is defined with the formula (Fig. 2a, c) [18]:

$$
V_{c s}=\frac{\pi}{6} \cdot d_{c s}^{3}
$$

where: $V_{c s}-$ spherical volume of PM or agglomerate concentrated without voids, $d_{c s}$ - diameter of solid particle without voids.

For spherical particles and agglomerates with voids, in order to determine the actual volume of PM (Fig. 2b, d), the volume of the voids should be taken into account [18]:

$$
V_{p z}=\frac{\pi}{6} \cdot d_{p p}^{3}=V_{c s}+V_{p p}
$$

where: $V_{p z}-$ spherical volume of PM or agglomerate with voids, $V_{p p}$ - total volume of void spaces in PM, $d_{p p}$ - PM diameter taking into consideration internal voids.

The mass $m_{c s}$ describing PM can be considered according to the accepted definition of density. The first is the density of solid matter $\rho_{c s}$ without voids:

$$
m_{c s}=V_{c s} \cdot \rho_{c s}=\frac{\pi}{6} \cdot d_{c s}^{3} \cdot \rho_{c s}
$$

where: $\rho_{c s}$ is density considering the solid and liquid phase: 


$$
\rho_{c s}=\frac{\rho_{a} \cdot V_{a}+\rho_{b} \cdot V_{b}+\ldots}{V_{a}+V_{b}+\ldots}
$$

where: $\rho_{a} \cdot V_{a}+\rho_{a} \cdot V_{a}+\ldots-\mathrm{PM}$ solid and liquid phase characterizing parameters.

The second definition uses density with voids $\rho_{p z}$ :

$$
m_{c s}=V_{p z} \cdot \rho_{p z}=\frac{\pi}{6} \cdot d_{p p}^{3} \cdot \rho_{p z}
$$

where: $\rho_{p z}-\mathrm{PM}$ density with voids:

$$
\rho_{c s}=\frac{\rho_{a} \cdot V_{a}+\rho_{b} \cdot V_{b}+\ldots}{V_{a}+V_{b}+\ldots}
$$

Assuming that the PM does not contain empty spaces in its structure, then the values are equal $\rho_{c s}=\rho_{p z}$. In the paper by Baron at al. [19] assumed density inequality $\rho_{c s}>\rho_{p z}$ and determined the fraction of PM volume taken up by void spaces:

$$
\beta=\left(\frac{\rho_{c s}}{\rho_{p z}}\right)^{1 / 3}
$$

A defined Baron coefficient allows to describe the relation between spherical or agglomerate diameters with and without empty spaces:

$$
d_{p p}=\beta \cdot d_{c s}
$$

In the research field of PM distribution, the value is described using the diameter $d_{a}$ defined as the diameter corresponding to the electrical charge of particle. For spherical particles and concentrated agglomerates it is described by:

$$
d_{a}=d_{c s}=d_{p p}
$$

while the diameter $d_{a}$ for PM in the form of dispersed agglomerates is described by:

$$
d_{a}>d_{p p}
$$

The size of the initial particles, their formation and the amount of voids all determine the PM structures. This has a direct effect on the diameter distribution and this also applies to density differences:

$$
\rho_{c s}>\rho_{p z}
$$

Such relations directly affect the mass and the course of PM decomposition. The biggest differences in measurements concern the expanded particle agglomerates with internal voids, isolated from the atmosphere of the medium in which the particle is located. In this case, the measuring apparatus identifies the compounds to be measured as large diameter particles but having a small mass. This results in different shapes of the characteristics of raw exhaust gas particle distribution curve and the distribution curve after chemical treatment in exhaust gas aftertreatment systems. It should be noted that sintering of particles has a significant effect on the PM agglomerate mass distribution after chemical treatment in the exhaust gas aftertreatment system. This especially applies to agglomerates with a dispersed structure, leading to a reduction in the volume ratio of PM to its density. Another phenomenon is agglomeration and the reshaping of agglomerates as a result of collisions. This process occurs both in the exhaust system and in the ducts and open pores of the particulate filter walls. This is another reason for the decrease of the PM volume to mass ratio.

In literature, the soot emitted from CI engines is mainly analyzed according to three criteria: the type of the engine, the emission standards of the exhaust gas components that the engine meets and the parameters of its operation (Fig. 3). The soot breakdown according to the second mentioned criterion is mainly attributable to a change in the version of direct fuel injection systems. This is about changing the parameters of injection pressure, droplet size and dose distribution. It also highlights the optimization of the combustion process as well as the use of modern exhaust gas treatment systems.
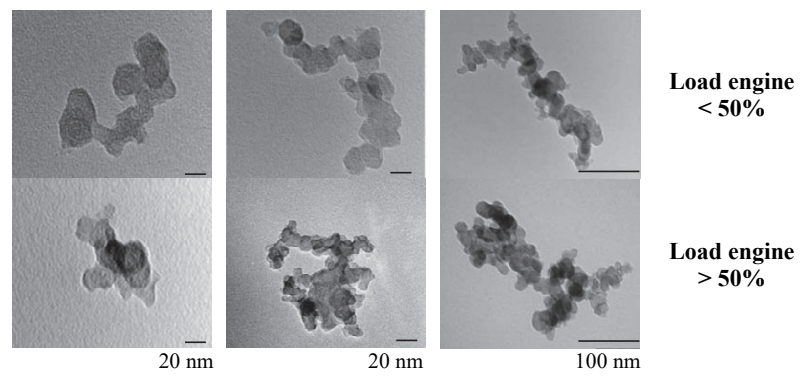

Fig. 3. TEM images of various soot aggregates emitted at different loads from a heavy duty vehicle engine [20].

\section{Research methodology}

\subsection{Tested vehicles}

Two HDVs were used for the measurements. The first one - designated as vehicle A - was an articulated lorry designed for long haulage of goods with a maximum authorized mass of over $16,000 \mathrm{~kg}$ (Tab. 1). It was equipped with a V8 engine with displacement of $15.6 \mathrm{dm}^{3}$. It generated a maximum output power of $P=$ $=412 \mathrm{~kW}(560 \mathrm{hp})$ at $1900 \mathrm{rpm}$ and maximum torque of $T=2700 \mathrm{~N} \cdot \mathrm{m}$ in the engine speed range of 1100-1400 rpm. The engine complied with the Euro $\mathrm{V}$ emission standard and was equipped with an selective catalytic reduction (SCR) system. During the measurements, vehicle A was loaded with a load of $25,000 \mathrm{~kg}$. The vehicle was also fitted with a driver monitoring system. The system, thanks to a continuous analysis of the signals from a series of sensors, provides real time hints and, at the end of the trip, generates a report on the driving style. The hints and the evaluations are presented and there are 4 categories: driving uphill, predicting, braking and gear shifts. The idea behind the system is to improve the driving skills in terms of fuel consumption 
and proper use of modern solutions such as: automatic transmission, retarder or the electronic braking system (EBS).

The second vehicle (B) was an 18 meter long city bus. As a source of propulsion, it used an 6-cylinder inline internal combustion engine with a displacement of $9.2 \mathrm{dm}^{3}$ generating a maximum power of $P=231 \mathrm{~kW}$ at $1900 \mathrm{rpm}$. It complied with the EEV (enhanced environmentally friendly vehicle) emission standard and was equipped with a continuous regeneration trap (CRT) and SCR catalytic system. The first of these is the combination of a diesel particulate filter (DPF) and an oxidation catalyst (DOC). The vehicle was loaded during the measurements with a load corresponding to the maximum number of passengers it can carry.

Table 1. Tested vehicles technical parameters.

\begin{tabular}{|c|c|}
\hline \multicolumn{3}{|c|}{ Vehicle A - tractor with trailer } \\
\hline & Displacement: $15.6 \mathrm{dm}^{3}$ \\
Maximum power: \\
$412 \mathrm{~kW} @ 1900 \mathrm{rpm}$ \\
Maximum torque: \\
Vehicle B - urban bus \\
\hline \\
\hline
\end{tabular}

\subsection{Test routes}

For the vehicle A authors selected a road portion of the length of $27 \mathrm{~km}$ (Tab. 2). The chosen route characterizes the operation of vehicles accurately of the GVW (gross vehicle weight) exceeding $16,000 \mathrm{~kg}$ (long haulage) in the area where the measurements were carried out. The test route started and ended in the industrial zone (point A) where a production facility is located at which approximately 50 heavy-duty vehicles are handled daily. The test route can be divided into two portions: a drive on the municipal roads (portion $\mathrm{A}-\mathrm{B}$ ) and national and regional roads. The drive on the national regional/roads depends on the driving direction from/to the entrance to the A2 expressway (Koło) (point D). In the case of driving to the 'Koło' expressway entrance to the route went through the sections $\mathrm{B}-\mathrm{C}$ and $\mathrm{C}-\mathrm{D}$. In the reverse situation i.e. exiting the expressway and driving to the production facility via bypasses: sections $\mathrm{D}-\mathrm{C}$ and $\mathrm{C}-\mathrm{B}$ (on the $\mathrm{D}-\mathrm{C}$ road portion heavy duty trucks exceeding GVW of $7000 \mathrm{~kg}$ are not allowed.) The above route can be deemed representative of the national transport and logistic infrastructure - representing the road infrastructure and the distribution of production facilities in small and medium-sized towns. For vehicle B, the route was dedicated to public transport buses and was a regular bus route in Poznan. In the hours when the study was conducted, it was one of the busiest lines serviced by the municipal communication company in Poznań. It had 46 stops and started in the northern part of town (Sobieskiego). Then ran through the center and ended in the southern part of town (Dębina) near the A2 motorway. Its total length was $16 \mathrm{~km}$.

Table 2. Test routes characteristics [21].

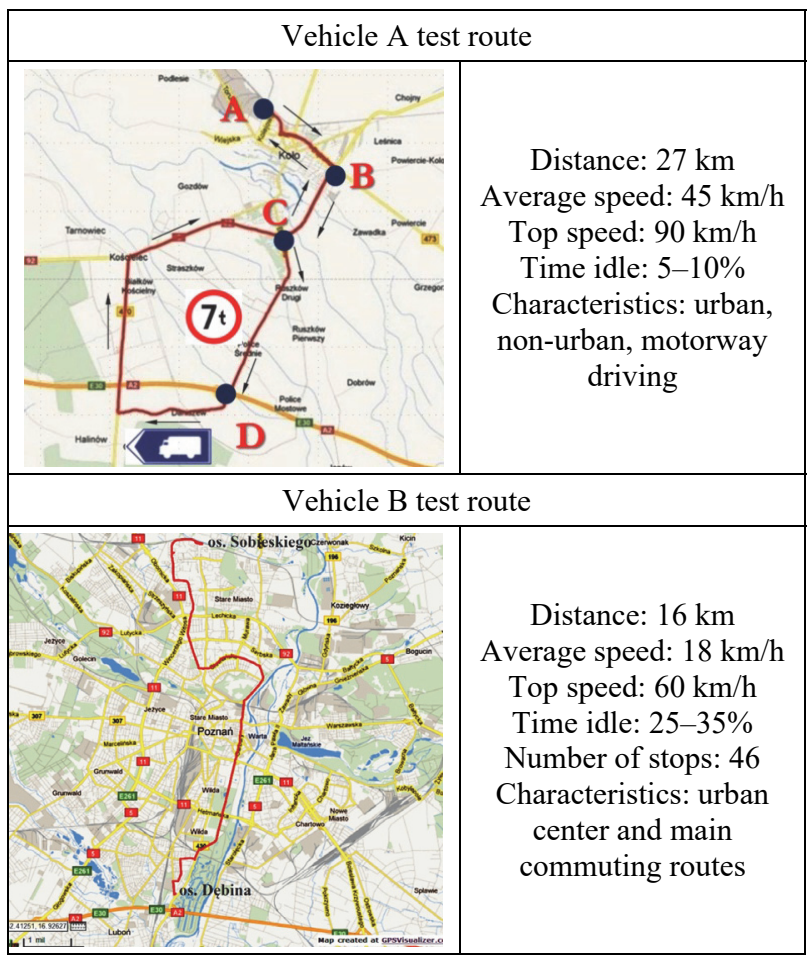

\subsection{Measurement equipment}

The purpose of the research was to analyze the mass, number and size distribution of emitted particles. For this reason, three instruments from the PEMS group (portable emission measurement system) were used: Semtech DS from Sensors Inc., Micro Soot Sensor from AVL and Engine Exhaust Particulate Sizer from TSI (Fig. 4). The first of these is dedicated to gas measurement of exhaust gas compounds. However, in this research measurement, the Semtech DS was used to measure the exhaust flow rate with the use of a Pitot tube. Also measured were: the speed and position of the vehicle (GPS), engine operating parameters (crankshaft speed and load) and the atmospheric conditions. The Micro Soot Sensor was used to measure the concentration of particulate matter, which was based on the determination of the carbon content of the molecule using the photoacoustic method. The exhaust gas sample is subjected to radiation with modulated light, which results in alternating heating and cooling of the sample, thereby changing its size periodically and generating vibration of the medium. Thanks to the use of sensitive microphones tuned to a certain amplitude and frequency, a sound wave is recorded. However, it occurs only when there is a particulate in the sample to be tested - then the impulse is directly proportional to the particulate 
concentration. Otherwise the microphones will not register any signal. For correct operation of the Micro Soot Sensor, it is necessary to dilute the flue gas sample to prevent condensation of the solids and to maintain their proper temperature.

Measurement of the number and dimensional distribution of particle diameters was done using an Engine Exhaust Particulate Sizer, which measures particles in the range of 5.6-560 nm. First, the exhaust sample is filtered from particulate matter larger than 1 $\mu \mathrm{m}$ in diameter. It is then directed to the charging electrode where the ions are generated. This combination of particles and electrical charge allows to classify particles by their size. The electrode is located at the very top of the device. The particles then enter the ring gap, which is the space between the two concentric cylinders. The gap is surrounded by a stream of clean air from the outside. The outlet cylinder is built in the form of a stack of very sensitive electrodes arranged in a ring in such a way that they are isolated from one another. The electrodes on one side are connected to a sensitive amplifier and grounded on the other. Such a connection creates an electric field between the cylinders made up of the electrodes. A mixture of fresh air and solid particles, which are charged positively, are repulsed from the high voltage electrode and passed between the sensitive electrodes. Particles striking the electrodes generate a current that is read out in real time by a driver with ten readings of different particle sizes per second. Example of use PEMS in research are presented in [2, 7, $9,10,13,22]$.

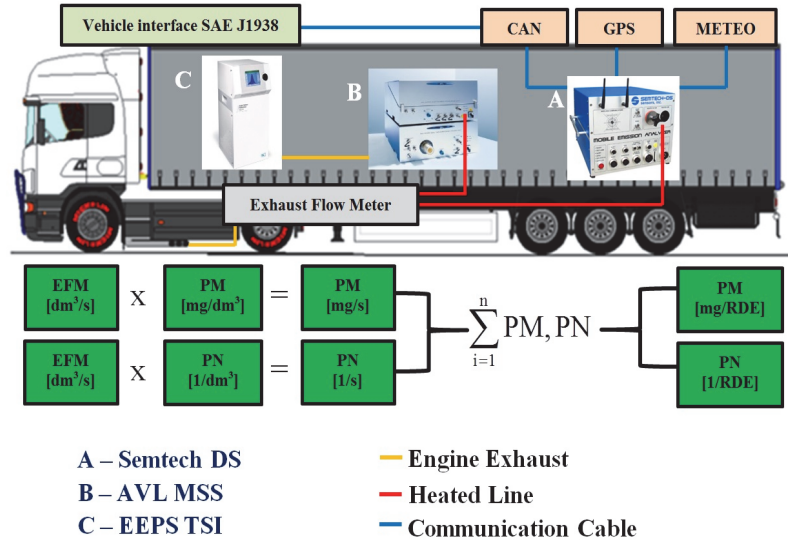

Fig. 4. PEMS type equipment used for the research.

As shown in the diagram depicted in Fig. 4, the values of the mass and number concentration of particles were multiplied by the exhaust gas flow, thereby obtaining the streams of the their volumes. After adding them, the mass and number of particles from the entire RDE test were obtained. By referring these values to the road traveled by the vehicle and the work done by the engine, the road and specific particulate matter mass and particle number were obtained. Particle size distribution is presented as the sum of the number of particles in the range of 5.6-560 $\mathrm{nm}$.

\section{Research results}

\subsection{Parameters of researched vehicles in road tests}

The time-density characteristics (TD) are commonly used in the construction and optimization work done on internal combustion engines and entire propulsion systems. Using their assumptions, it is possible to determine, among others, the emission intensity of harmful exhaust compounds or the internal combustion engine time density in the crankshaft speed ranges and loads in a given measurement tests cycle. Therefore, it is possible to describe the motion of a vehicle as a discrete function. They also allow to describe the test drive characteristics for different speed ranges and acceleration values. The characteristics relating to the engine and vehicle operating parameters were performed for half-closed intervals. This resulted in more accurate analysis. In addition, consideration of traffic conditions is given to the vehicle being idle (speed and acceleration equal to 0 ), which is very important due to the specificity of the operation of city buses - vehicle B.

Registered data from the GPS positioning system and on-board diagnostic systems were used to develop the internal combustion engines and vehicles operating parameters in road tests (Fig. 5). The tested vehicles are classified as heavy vehicles and are similarly type approved in terms of exhaust emissions. However, the presented relations indicate that their typical operating conditions vary considerably. The heavy-duty vehicle A used for long-distance transport obtained a significant operating time density at constant speeds $\left(a=0 \mathrm{~m} / \mathrm{s}^{2}\right)$. In the vehicle speed interval $(16 \mathrm{~m} / \mathrm{s} ; 24 \mathrm{~m} / \mathrm{s}\rangle$ the operating time density of $25.3 \%$ was calculated for the entire test. For the idle interval, the operating time density was $2.4 \%$. The operating conditions contributed to achieving similar acceleration value ranges for acceleration greater and smaller than $0 \mathrm{~m} / \mathrm{s}^{2}$. For the city bus, a different characteristic distribution was obtained. The greatest operating time density being $24.3 \%$ for vehicle idle interval, which was a consequence of the way the vehicle was operated (i.e. the service of bus stops). For the interval of constant speed $(8 \mathrm{~m} / \mathrm{s} ; 12 \mathrm{~m} / \mathrm{s}\rangle$ the time density value of $9 \%$ was obtained. The vehicle drive system dynamics had the greatest influence on the distribution of acceleration greater than $0 \mathrm{~m} / \mathrm{s} 2$. For acceleration in the intervals $\left\langle-0.8 \mathrm{~m} / \mathrm{s}^{2} ; 0 \mathrm{~m} / \mathrm{s}^{2}\right)$ and $\langle 0$ $\left.\mathrm{m} / \mathrm{s}^{2} ; 0.8 \mathrm{~m} / \mathrm{s}^{2}\right)$ in the vehicle speed interval $(0 \mathrm{~m} / \mathrm{s} ; 10$ $\mathrm{m} / \mathrm{s}\rangle$ the operating time density was $16 \%$ and $23.7 \%$ respectively. The maximum speeds achieved by the vehicles in the test were: for vehicle $A-23.3 \mathrm{~m} / \mathrm{s}$ and for vehicle $\mathrm{B}-15.6 \mathrm{~m} / \mathrm{s}$.

Data obtained from the researched vehicles was analyzed with consideration given to the internal combustion engines operating parameters. For vehicle A the largest operating time density was $43.2 \%$ and $25.9 \%$ in two main intervals. The first of those occurred in the interval described by the speed parameters (1000 rpm; $1200 \mathrm{rpm}\rangle$ and engine load of $\langle 0 \% ; 80 \%\rangle$. The second one was recorded at the lowest engine loads in the 
a)
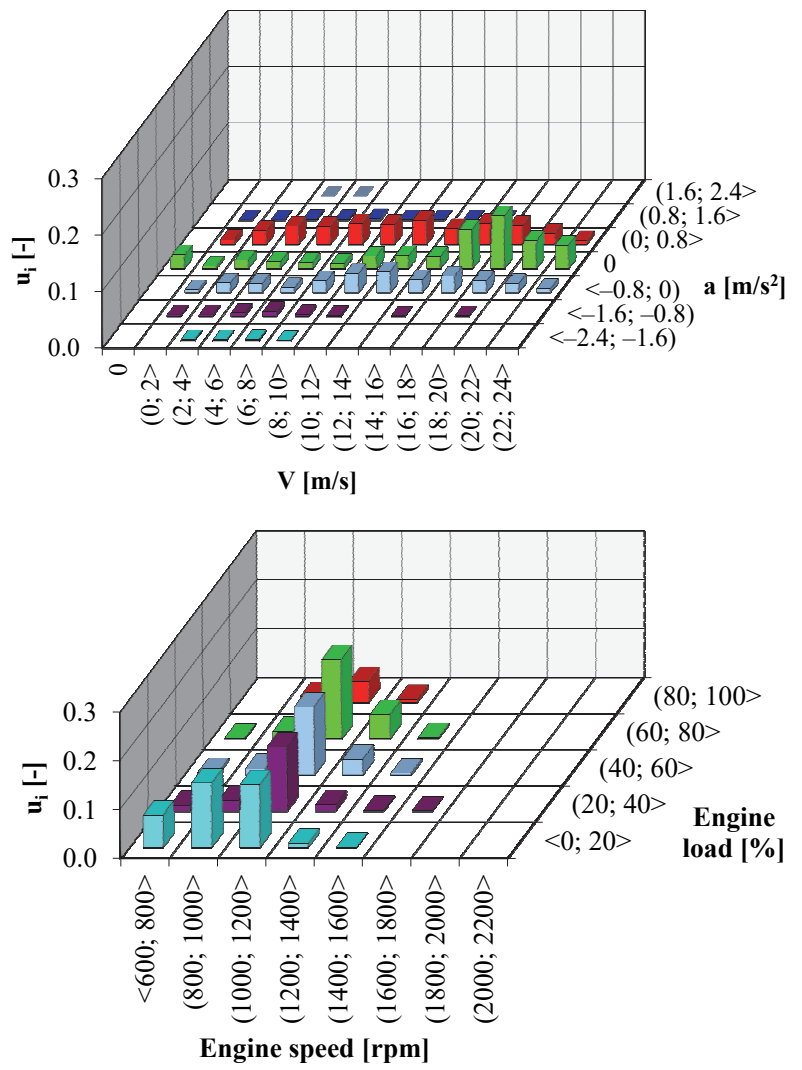

b)
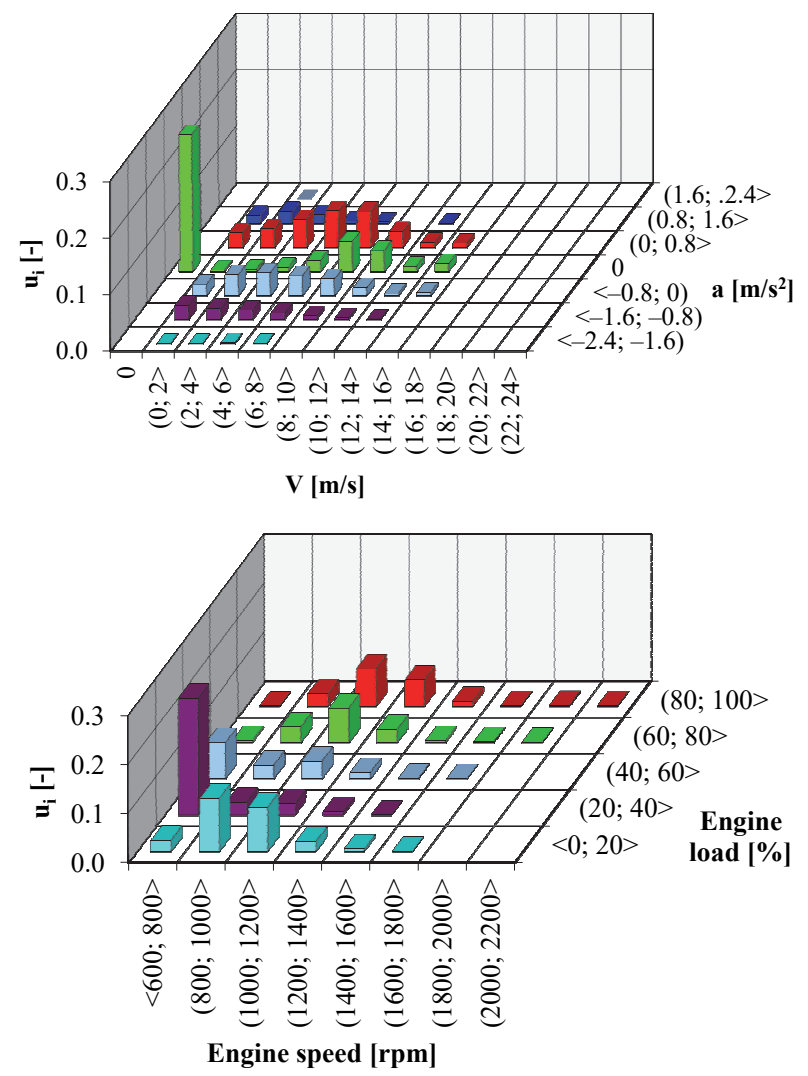

Fig. 5. Operating parameters of the tested vehicles in intervals of: speed - acceleration of vehicle, and crankshaft speed engine load: a) vehicle A, b) vehicle B. engine speed interval $(800 \mathrm{rpm} ; 1200 \mathrm{rpm}\rangle$. In terms of idle engine speed and minimum load, the obtained time density was $6.5 \%$. The remainder of the individual intervals yielded no more than $4 \%$. The internal combustion engine of vehicle $\mathrm{B}$ had a much greater variation in its operating parameters, with the exception of one of the intervals characterized by the lowest crankshaft rotational speed and load interval of $(20 \%$; $40 \%\rangle$.

The time density in the aforementioned interval is $24 \%$. This value is due to the operating nature of the city bus - the high proportion of idle operation connected with the servicing of bus stops and traffic congestions led to a constant load on the engine. It should be noted that this is highly dependent on the number of functional systems used in the vehicle (such as: air conditioning, heating, pneumatic handling of doors, vehicle suspension, etc.). In other single intervals the time density did not exceed $5 \%$.

\subsection{Particle emissions in mass, number and size distribution in road tests}

PM emissions from modern combustion engines are a significant problem. In both CI and SI engines with direct injection systems and devices are being used increasingly more often to reduce the emission of this toxic compound in terms of mass and number. Among the most important of these solutions are high-pressure fuel injection with dose distribution and particulate filters. The first of these is a structural design that directly affects the combustion process. Very small drops evaporate more rapidly, resulting in a reduction of soot formation. The second solution allows the effective reduction of the PM emissions generated in the combustion process. However, the use of filters requires the ability to regenerate them and in such a way that will be as little a nuisance to the vehicle user as possible. This is a difficult issue that requires taking many aspects into account (the quality of the regeneration has a significant effect on the filter life).

The summary of the PM emissions per second from the road tests as a function of the engine performance is shown in Fig. 6. For vehicle A, a close dependence of the PM emissions on the engine load is evident. The effect of engine speed is only relevant for the first load range up to $20 \%$. For the most common operating parameter range, described by the following parameters: (1000 rpm; $1200 \mathrm{rpm}\rangle$ and $\langle 0 \% ; 80 \%\rangle$, PM emissions average $4.4 \mathrm{mg} / \mathrm{s}$. This is a small result compared to other intervals. For the highest load interval, the average $\mathrm{PM}$ emission is $13 \mathrm{mg} / \mathrm{s}$. Vehicle A was not equipped with a DPF system and therefore a higher average PM emission of $6.5 \mathrm{mg} / \mathrm{s}$ was achieved for the entire road test than for vehicle B.

The DPF filter used in the city bus contributed to an effective mass reduction of PM emissions, the average emission was $0.5 \mathrm{mg} / \mathrm{s}$. In this case, there is another tendency of the second order dependence on the operating parameters of the internal combustion engine. The emission value mainly depends on the crankshaft 
rotational speed and to a lesser extent on the engine load. For the maximum speed interval and the load interval of $(80 \% ; 100 \%)$ PM emission was determined at $1.6 \mathrm{mg} / \mathrm{s}$. For the highest time density interval recorded, the per second emission of the compound was $0.1 \mathrm{mg} / \mathrm{s}$.

a)

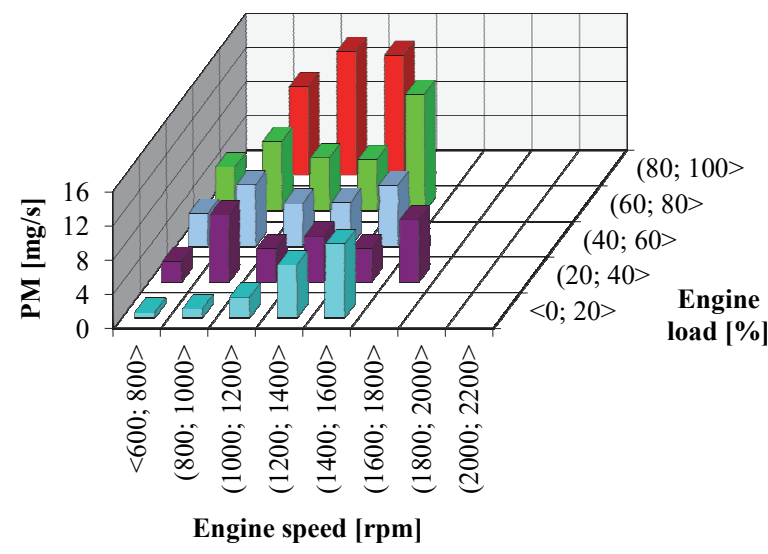

b)

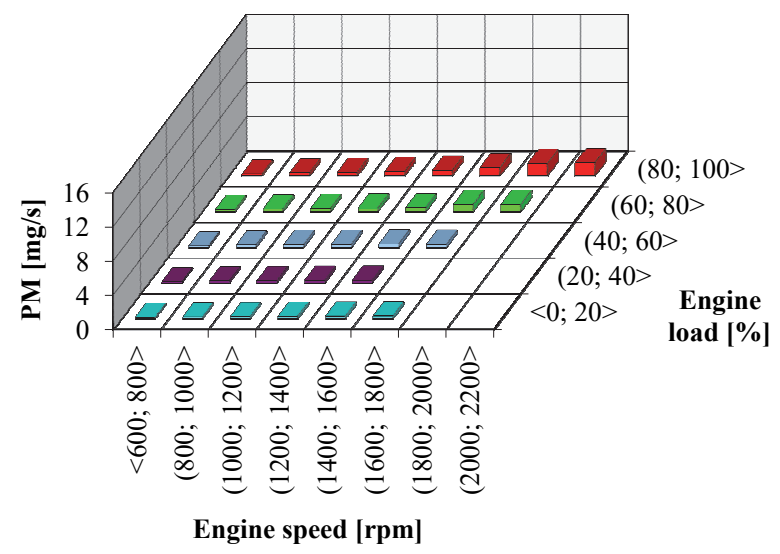

Fig. 6. PM emission intensity in the speed and torque intervals during road tests: a) vehicle A, b) vehicle B.

The road and specific PM emissions of tested vehicles were determined for the carried out drive tests (Fig. 7). The area of the engine operating parameters variability for vehicle A was smaller compared to the city bus (vehicle B). This is advantageous in terms of PM emissions because it largely depends on the contribution from the dynamic operating conditions frequent changes in engine speed and load. However, the lack of an exhaust aftertreatment system has resulted in higher emissions than for vehicle $\mathrm{B}$ as a result. For longdistance heavy vehicle, the road PM emission was $0.39 \mathrm{~g} / \mathrm{km}$, while the specific PM emission was $0.15 \mathrm{~g} /(\mathrm{kW} \cdot \mathrm{h})$. In the tests of the urban bus, the values were lower by $87.2 \%$ and $86.6 \%$, respectively. The vehicle B's internal combustion engine worked in a greater range of operating parameters variability, which was due to its operating conditions. However, for the interval where the highest time density occurred, the PM emission rate was characterized by low values. This translated into the obtained results of the road and specific PM emissions.

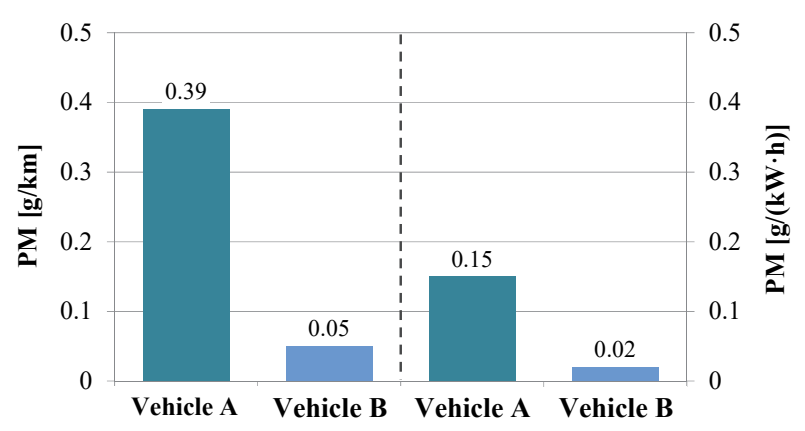

Fig. 7. Comparison of road and specific PM emissions based on road tests.

The vehicle A PN emission rate depended on both the crankshaft rotation speed and the engine load (Fig. 8). Within the interval of the highest time density, the average emission was $2.5 \mathrm{E}+10$ particles per second. The maximum emission rate of $\mathrm{PN}$ of $7.3 \mathrm{E}+10$ per second was recorded in the engine speed interval (1400 rpm; $1600 \mathrm{rpm}\rangle$ and load $(20 \% ; 40 \%)$. In the maximum load interval, the average emission rate was $3.4 \mathrm{E}+10$ per second and for the entire operating range reached $2.7 \mathrm{E}+10$ per second. The comparison of the obtained emission characteristic with the mass PM emission rate (Fig 6a) indicates that there is no unambiguous relationship between the PM mass and the number emitted. This conclusion is based on vehicle $\mathrm{A}$ in which the PM emission is limited to only through the applied structural engineering in the internal combustion engine itself.

Different relations were obtained using the distribution of the characteristics measured for the city bus. For vehicle B, a similar emission rate of PN and PM was obtained. This means that the performance of the exhaust aftertreatment system used depends primarily on the crankshaft rotational speed. At the operating point with the highest time density, the PN emission rate was $4.2 \mathrm{E}+8$ per second. For the entire road test, the average value was $3.9 \mathrm{E}+8$ per second, and in the highest load interval it was $4.1 \mathrm{E}+8$ per second. The highest PN emission rate $7 \mathrm{E}+9$ per second occurred in two single engine speed intervals of $(1400 \mathrm{rpm} ; 1800 \mathrm{rpm}\rangle$ for engine load of $(40 \% ; 60 \%)$.

Due to the toxic effect of PM on living organisms, it is necessary to be aware of their emission from vehicles including for their size distribution. Nanoparticles are carcinogenic and, according to the environmental protection initiatives, their numbers should be reduced. Fig. 9 shows the total PN emissions with respect to measured particle diameters. However, it should be noted that the test vehicles have travelled different routes, so it is not possible to compare the values themselves, but only the characteristics of the obtained size distributions. For vehicle A the highest PN emission (above 1.9E $+121 / \mathrm{RDE}$ ) occurred in the diameter intervals $\langle 6 \mathrm{~nm}, 10.8 \mathrm{~nm}\rangle$ and $\langle 29.4 \mathrm{~nm} ; 52.3 \mathrm{~nm}\rangle$ (Fig. 9). The emission totals in these intervals were: $2.8 \mathrm{E}+131 / \mathrm{RDE}$ and $1.4 \mathrm{E}+131 / \mathrm{RDE}$ respectively. For the interval between the indicated range, a lower PN emission value was recorded, on average $7.4 \mathrm{E}+11$ 1/RDE. For single diameters above $254 \mathrm{~nm}$, the obtained 
a)

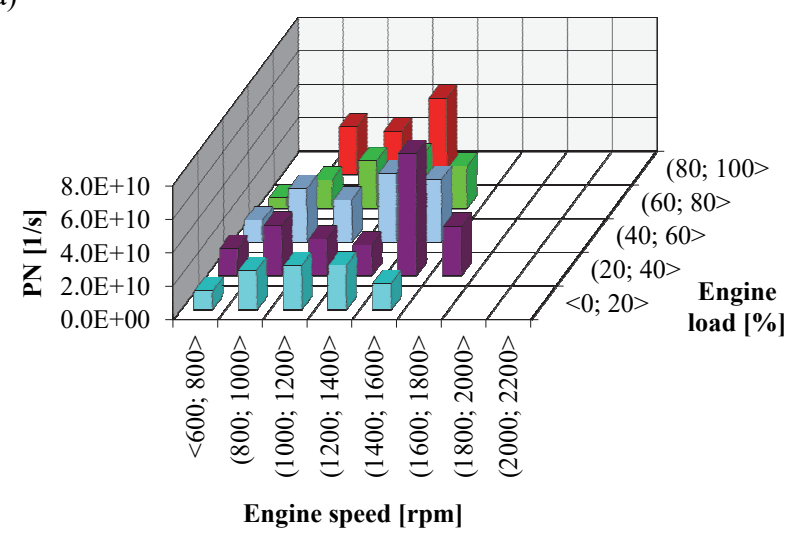

b)

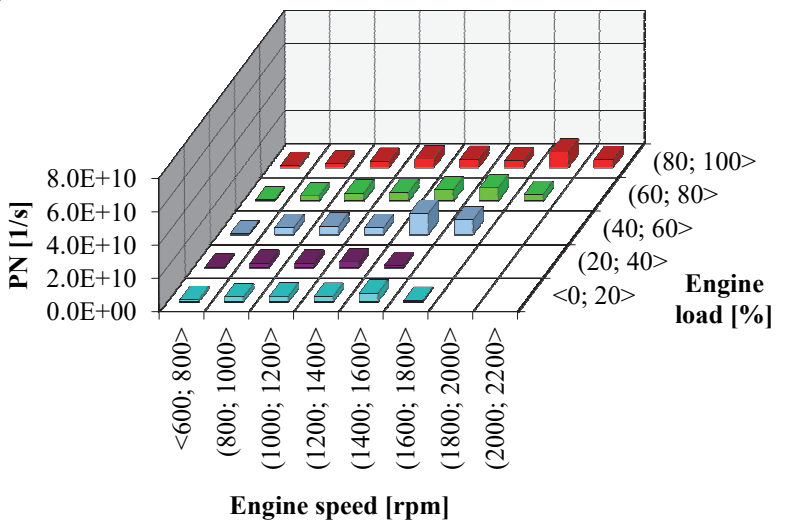

Fig. 8. PN emissions intensity in rotational speed and torque intervals during road tests: a) vehicle $\mathrm{A}, \mathrm{b}$ ) vehicle $\mathrm{B}$.

a)

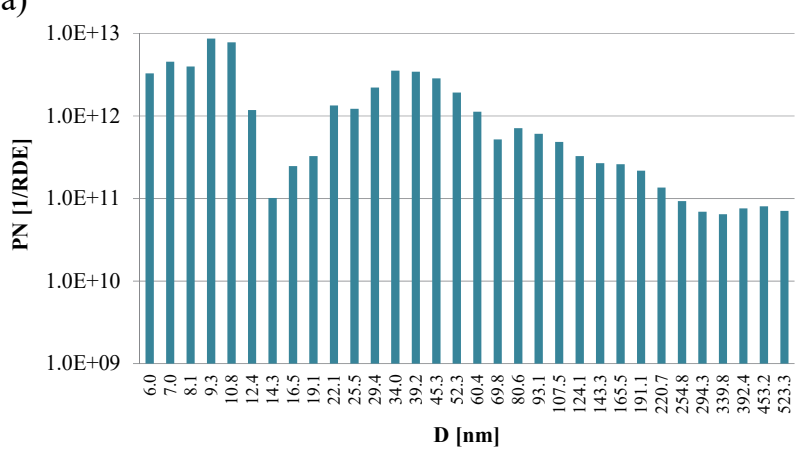

b)

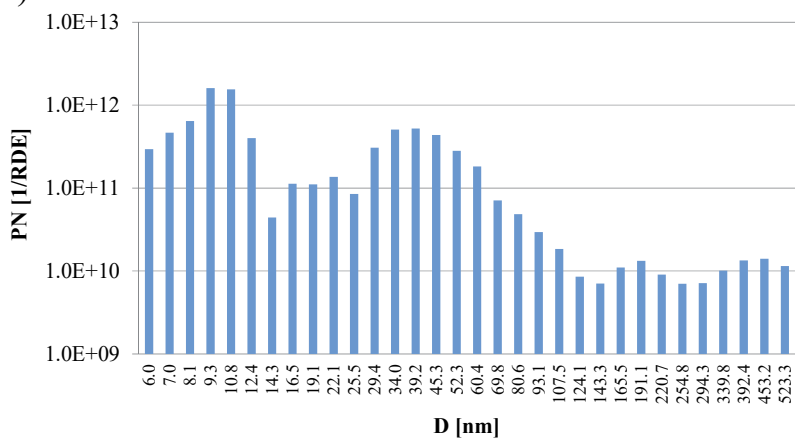

Fig. 9. Summary of $\mathrm{PN}$ emission as a function of particle diameters during road tests: a) vehicle $\mathrm{A}, \mathrm{b}$ ) vehicle $\mathrm{B}$.

results were not greater than $7.9 \mathrm{E}+10$. Smaller PN emission values were obtained for each diameter in case of the city bus, however, the characteristic of the size distribution remains very similar. It can therefore be assumed that the equipped filter limits the PN emissions for all the measured particle diameters. For particle diameters up to $10.8 \mathrm{~nm}$ over the whole test route, the emission value of $4.6 \mathrm{E}+121 / \mathrm{RDE}$ was obtained. The PN emission did not exceed 1.4E+10 1/RDE for diameters greater than $124 \mathrm{~nm}$.

In order to compare the obtained PN emissions for the tested vehicles, road and specific indicators have been identified (Fig. 10). As with the PM mass comparison, the city bus was characterized by more favorable environmental indicators. This was also the result of using a DPF system that effectively reduced the number of particles in the exhaust gases. The road PN emission of vehicle A was $1.9 \mathrm{E}+12$ per $\mathrm{km}$, while the specific PN emission was $7.45 \mathrm{E}+111 /(\mathrm{g} / \mathrm{kW} \cdot \mathrm{h})$. The second test vehicle achieved results respectively $27 \%$ and $24.7 \%$ lower than vehicle A. The discrepancies are lower than in the case of mass indicators. This means that the filter used in the city bus effectively reduces the PM emission by weight, so according to the accepted research method, by limiting the larger diameter particles.

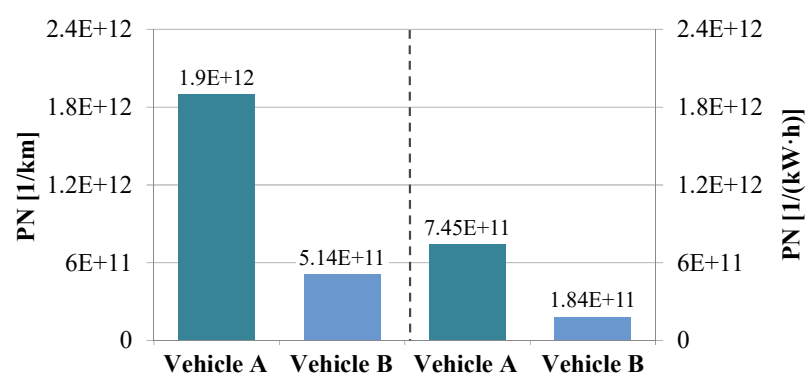

Fig. 10. Comparison of road and specific PN emission based on road tests.

\section{Conclusions}

The restriction of regulations describing the emission standards for toxic compounds is a major factor in the continuous development of internal combustion engines and exhaust gas aftertreatment systems. In these activities, particular emphasis is placed on limiting $\mathrm{NO}_{\mathrm{x}}$, $\mathrm{PM}$, emissions, as well as $\mathrm{CO}_{2}$ emission, which is directly related to the vehicle fuel consumption. Within the scope of PM regulation, not only limits on emitted mass are introduced but also on emitted numbers. Effective research on the environmental performance of vehicles is increasingly being used in real driving conditions. They allow for a comprehensive assessment of the pollutant emissions of a given test vehicle in a wide and variable range of engine operating parameters.

The article discusses the causes of PM generation and emission in internal combustion engines. The results of road tests on PM emissions in terms of mass, number and size distribution were also presented. The tested vehicles were both heavy vehicles: a tractor with a trailer and an eighteen meter city bus. The test conditions have been selected in such a way so that they as closely as possible reflect the vehicles real operating conditions. 
For this reason, vehicle A was working in a much smaller range of variability than vehicle $\mathrm{B}$. The analysis of the environmental indicators obtained implies that the second test vehicle has obtained more favorable final values. This was due to the use of an exhaust aftertreatment system in the form of a DPF. The road and specific PM emissions for this vehicle were respectively $87.2 \%$ and $86.6 \%$ lower than for the other vehicle, while the PN emissions were $27 \%$ and $24.7 \%$ lower. This means that the exhaust aftertreatment system effectively reduces the emission of higher mass particles, those with a larger diameter (according to the accepted methodology). Particle size distribution analysis for PN indicates that the obtained results have similar characteristics for both test vehicles. The determined relations, supplemented with data of the test conditions, can be very useful for carrying out various types of further research and development work. This includes the modification of the exhaust aftertreatment systems components as well as the control of combustion engines operation.

The research was funded by the National Centre for Research and Development (Narodowe Centrum Badań i Rozwoju) research project within the INNOTECH Programme (contract No. INNOTECH-K2/IN2/36/182269/NCBR/12).

\section{References}

1. J. Merkisz, J. Pielecha, S. Radzimirski, Springer Tracts on Transportation and Traffic 4, 1-170 (2014), DOI: 10.1007/978-3-319-02705-0

2. J. Merkisz, J. Pielecha, Springer Tracts on Transportation and Traffic 8, 131-139 (2015), DOI: 10.1007/978-3-319-15928-7_10

3. Z. Stepien, J. Czerwinski, P. Comte, S. Oleksiak, Energy \& Fuels 30, 7268-7276 (2016), DOI: 10.1021/acs.energyfuels.6b00583

4. M. Pośniak, Medycyna Pracy 54, 389-393 (2003)

5. R. Jasinski, J. Pielecha, J. Markowski, E3S Web of Conferences 10, UNSP 00030 (2016), DOI: $10.1051 / \mathrm{e} 3$ sconf/20161000030

6. A. Suchecki, J. Nowakowski, T. Knefel, Transport Means - Proceedings of the International Conference, 194-197 (2014)

7. J. Merkisz, J. Pielecha, P. Lijewski, A. MerkiszGuranowska, M. Nowak, WIT Transactions on Ecology and the Environment 174, 27-38 (2013), DOI: 10.2495/AIR130031

8. J. Szczepaniak, T. Pawlowski, R. Grzechowiak, J. Kromulski, J. Rutkowski, Applied Engineering in Agriculture 31, 709-716 (2015)

9. J. Merkisz, J. Pielecha, Springer Tracts on Transportation and Traffic 8, 69-92 (2015), DOI: 10.1007/978-3-319-15928-7_7

10. J. Merkisz, P. Lijewski, P. Fuc, S. Weymann, Eksploatacja i Niezawodnosc - Maintenance and Reliability 15, 364-368 (2013)
11. Commission Regulation (EU) No 582/2011 of 25 May 2011 implementing and amending Regulation (EC) No 595/2009 of the European Parliament and of the Council with respect to emissions from heavy duty vehicles (Euro VI) and amending Annexes I and III to Directive 2007/46/EC

12. Commission Regulation (EU) 2016/427 of 10 March 2016 amending Regulation (EC) No $692 / 2008$ as regards emissions from light passenger and commercial vehicle (Euro 6)

13. J. Pielecha, J. Merkisz, J. Markowski, R. Jasinski, E3S Web of Conferences 10, UNSP 00073 (2016), DOI: $10.1051 / \mathrm{e} 3$ sconf $/ 20161000073$

14. O.R. Ignatov, A.P. Polivyanchuk, Combustion Engines 148, 48-52 (2012)

15. J.O. Müller, D.S. Su, R.E. Jentoft, J. Kröhnert, F.C. Jentoft, R. Schlögl, Catalysis Today 102, 259-265 (2005)

16. P. Fuc, L. Rymaniak, A. Ziolkowski, WIT Transactions on Ecology and the Environment 174, 207-218 (2013), DOI: 10.2495/AIR130181

17. H. Richter, J.B. Howard, Progress in Energy and Combustion Science 26, 565-608 (2000)

18. P.F. Decarlo, J.G. Slowik, R. Douglas, P. Davidovits, J.L. Jimenez, Aerosol Science and Technology 38, 1185-1205 (2004)

19. T.L. Barone, A.A. Lall, J.M.E. Storey, G.W. Mulholland, V.Y. Prikhodko, J.H. Frankland, J.E. Parks, M.R. Zachariah, Energy \& Fuels 25, 19781988 (2011)

20. A. Soewono, S. Rogak, Aerosol Science and Technology 45, 1206-1216 (2011)

21. http:/gpsvisualizer.com (access: 24.04.2017)

22. P. Lijewski, J. Merkisz, P. Fuc, Croatian Journal of Forest Engineering 34, 113-122 (2013) 